\section{JURNAL EKONOMI EFEKTIF}

ISSN : $2622-8882$, E-ISSN : 2622-9935

Jurnal Ekonomi Efektif, Vol. 4, No. 2, Januari 2022

@ Prodi Manajemen Fakultas Ekonomi

Universitas Pamulang

\title{
PENGARUH LINGKUNGAN KERJA TERHADAP KINERJA KARYAWAN PADA PT PRIMA ABADI DI JAKARTA
}

\author{
Ihsan Suryadi ${ }^{1}$, Sachro Yusuf ${ }^{2 *}$ \\ Universitas Pamulang, Tangerang Selatan, Banten, Indonesia \\ ihsansuryadi99@gmail.com ${ }^{1}, \underline{\text { dosen01228@unpam.ac.id }{ }^{2 *}}$
}

Manuskrip: November -2021; Ditinjau: November: -2021; Diterima: Desember-2021; Online: Januari -2022; Diterbitkan: Januari-2022

\begin{abstract}
ABSTRAK
Penelitian ini bertujuan untuk mengetahui pengaruh lingkungan kerja terhadap kinerja karyawan pada PT. Prima Abadi di Jakarta. Metode yang digunakan adalah explanatory research dengan sampel sebanyak 82 responden. Teknik analisis menggunakan analisis statistik dengan pengujian regresi, korelasi, determinasi dan uji hipotesis. Hasil penelitian ini variabel lingkungan kerja diperoleh nilai rata-rata skor sebesar 3,401 dengan kriteria baik. Variabel kinerja karyawan diperoleh nilai rata-rata skor sebesar 3,816 dengan kriteria baik. Lingkungan kerja berpengaruh positif dan signifikan terhadap kinerja karyawan dengan nilai persamaan regresi $\mathrm{Y}=11,598+0,781 \mathrm{X}$, dan nilai koefisien korelasi 0,746 atau memiliki tingkat hubungan yang kuat dengan nilai determinasi 55,7\%. Uji hipotesis diperoleh signifikansi $0,000<0,05$.
\end{abstract}

\section{Kata Kunci: Lingkungan kerja, Kinerja Karyawan}

\begin{abstract}
This study aims to determine the effect of the work environment on employee performance at PT. Prima Abadi in Jakarta. The method used is explanatory research with a sample of 82 respondents. The analysis technique uses statistical analysis with regression, correlation, determination and hypothesis testing. The results of this study of the work environment variable obtained an average score of 3,401 with good criteria. the performance variable obtained an average score of 3.816 with good criteria. The work environment has a positive and significant effect on employee performance with the value of the regression equation $Y=11,598+0.781 X$, and the correlation coefficient value of 0.746 or has a strong relationship with a determination value of 55.7\%. Hypothesis testing obtained a significance of $0.000<0.05$
\end{abstract}

Keywords: Work Environment, Employee Performance 


\section{PENDAHULUAN}

\section{A. Latar Belakang}

Peranan lingkungan kerja sangat penting diperhatikan oleh perusahaan, mengingat dengan lingkungan kerja yang baik mampu dalam meningkatkan kinerja karyawan dalam perusahaan. Karena ingkungan kerja merupakan salah satu hal yang dapat memotivasi karyawan untuk bekerja sangat baik. Lingkungan kerja yang baik dapat dilihat dari suasana kerja (yang meliputi: penerangan yang cukup, sirkulasi udara yang baik, tersedianya alat-alat pengamanan, suara bising yang ditekan seminimal mungkin), dari kondisi hubungan karyawan serta tersedianya fasilitas pendukung lain. Dengan adanya fasilitas - fasilitas yang diberikan perusahaan, maka hal ini sangat berpengaruh langsung terhadap semangat kerja karyawan sehingga kinerja pun meningkat. Ini adalah salah satu permasalahan yang sering di hadapi perusahaan yaitu bagaimana meningkatkan dan menjaga lingkungan kerja yang baik.

PT. Prima Abadi sebagai suatu perusahaan manufaktur yang menerapkan sistem jam kerja masuk dan pulang pada Shift I sampai dengan sif III memiliki standar kerja karyawan shift dan non shif adalah presentase produk yang dihasilkan melebihi target produk yang ditetapkan perusahaan dan persentase absensi karyawan yang dilihat setiap harinya. Hal ini penting sekali diperhatikan oleh pihak perusahaan dengan memperhatikan suasana dan lingkungan kerja yang mendukung guna mendorong karyawan untuk memberikan hasil yang terbaik. Lingkungan kerja yang kondusif selain dapat memotivasi kerja karyawan, dapat juga meningkatkan semangat dan kegairahan kerja karyawan yang bisa menjadikan kinerja karyawan akan maksimal. Namun pada kenyataannya kinerja karyawan semakin menurun.

Lingkungan kerja adalah salah satu faktor yang semestinya lebih diperhatikan oleh perusahaan karena sangat berpengaruh terhadap keadaan kinerja karyawan. Karena adanya lingkungan kerja yang kondusif dan nyaman akan mempengaruhi semangat kerja karyawan sehingga karyawan termotivasi untuk mencapai tujuan- tujuan perusahaan. Begitu juga sebaliknya, apabila lingkungan kerja yang ada tidak memadai atau kurang kondusif, motivasi, semangat kerja, kinerja karyawan akan menurun.

Dengan adanya lingkungan kerja yang kondusif pada karyawan diharapkan kinerja karyawan meningkat. Lingkungan kerja ada perusahaan ini tentunya masih banyak kekurangan, sebab lingkungan kerja mampu mendorong karyawan untuk bekerja lebih optimal. Selain itu dapat juga meningkatkan semangat dan kegairahan kerja karyawan yang tentunya menjadikan kinerja karyawan akan menjadi maksimal.

Peningkatan kinerja karyawan dapat dilakukan dengan berbagai cara, salah satunya memperbaiki lingkungan kerja menjadi lebih kondusif dan nyaman. Meskipun pengaruh lingkungan kerja ini masih minim dibandingkan faktor lain, namun hal ini yang bisa mengakibatkan kerugian besar perusahaan untuk mengontrol sistem kerja karyawannya.

Dengan bertitik tolak pada uraian diatas maka penulis tertarik untuk melakukan penelitian yang berjudul " Pengaruh Lingkungan Kerja Terrhadap Kinerja Karyawan PT. Prima Abadi di Jakarta".

\section{B. Rumusan Masalah}

1. Bagaimana lingkungan kerja pada PT. Prima Abadi di Jakarta ?.

2. Bagaimana kinerja karyawan pada PT. Prima Abadi di Jakarta ?.

3. Adakah pengaruh antara lingkungan kerja terhadap kinerja karyawan pada PT. Prima Abadi di Jakarta?. 


\section{Tujuan Penelitian}

1. Untuk mengetahui kondisi lingkungan kerja pada PT. Prima Abadi di Jakarta.

2. Untuk mengetahui kondisi kinerja karyawan pada PT. Prima Abadi di Jakarta.

3. Untuk mengetahui pengaruh lingkungan kerja terhadap kinerja karyawan pada PT. Prima Abadi di Jakarta.

\section{TINJAUAN PUSTAKA}

\section{Lingkungan Kerja}

Lingkungan kerja adalah keseluruhan sarana prasarana kerja yang ada disekitar karyawan yang sedang melaksanakan pekerjaan yang dapat mempengaruhi pekerjaan itu sendiri, lingkungan kerja didesain sedemikian rupa agar dapat tercipta hubungan kerja yang mengikat pekerja dengan lingkungan. Menurut Sedarmayanti (2017) lingkungan kerja adalah keseluruhan alat perkakas dan bahan yang dihadapi, lingkungan sekitarnya dimana seseorang bekerja, metode kerjanya serta pengaturan kerjanya baik sebagai perseorangan maupun kelompok.

\section{Kinerja Karyawan}

Menurut Sutrisno (2020:99) produkivitas adalah hubungan antara keluaran (barang-barang atau jasa) dengan masukan (tenaga kerja, bahan, uang). Kinerja merupakan ukuran efisiensi produktif. Suatu perbandingan antara hasil keluaran dan masukan. Masukan sering dibatasi dengan tenaga kerja, sedangkan keluaran diukur dalam kesatuan fisik, bentuk, dan nilai.

\section{METODE PENELITIAN}

\section{Populasi}

Yang dijadikan sebagai populasi dalam penelitian ini adalah responden yang berjumlah 82 responden PT. Prima Abadi di Jakarta

\section{Sampel}

Teknik pengambilan sampling dalam penelitian ini adalah sampel jenuh, dimana semua anggota populasi dijadikan sebagai sampel. Dengan demikian sampel dalam penelitian ini sampel yang digunakan berjumlah 82 responden.

\section{Jenis Penelitian}

Jenis penelitian yang dipakai adalah asosiatif, dimana tujuannya adalah untuk mengetahui atau mencari keterhubungan antara variabel independen terhadap variabel dependennya

\section{Metode Analisis Data}

Dalam menganalisis data digunakan uji validitas, uji reliabilitas, analisis regresi linier sederhana, analisis koefisien korelasi, analisis koefisien determinasi dan pengujian hipotesis.

\section{HASIL PENELITIAN}

\section{Analisis Deskriptif}

Pada pengujian ini digunakan untuk mengetahui skor minimum dan maksimum skor tertinggi, ratting score dan standar deviasi dari masing-masing variabel. Adapun hasilnya sebagai berikut: 


\begin{tabular}{|c|c|c|c|c|c|}
\hline \multicolumn{6}{|c|}{$\begin{array}{c}\text { Tabel 1. Hasil Analisis Descriptiv } \\
\text { Descriptive Statistics }\end{array}$} \\
\hline 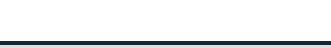 & $\mathrm{N}$ & Minimum & Maximum & Mean & Std. Deviation \\
\hline Lingkungan kerja (X) & 82 & 29 & 44 & 34.01 & 4.002 \\
\hline Kinerja Karyawan (Y) & 82 & 29 & 49 & 38.16 & 4.188 \\
\hline Valid N (listwise) & 82 & & & & \\
\hline
\end{tabular}

Lingkungan kerja diperoleh varians minimum sebesar 29 dan varians maximum 44 dengan ratting score sebesar 3,401 dengan standar deviasi 4,002. Skor ini termasuk pada rentang sakala 3,40 - 4,19 dengan kriteria baik atau setuju. Kinerja karyawan diperoleh varians minimum sebesar 29 dan varians maximum 49 dengan ratting score sebesar 3,816 dengan standar deviasi 4,188. Skor ini termasuk pada rentang sakala 3,40 - 4,19 dengan kriteria baik atau setuju.

\section{Analisis Kuantitatif}

Pada analisis ini dimaksudkan untuk mengetahui pengaruh variabel independen terhadap variabel dependen. Adapun hasil pengujian sebagai berikut:

\section{a. Analisis Regresi Linier Sederhana}

Uji regresi ini dimaksudkan untuk mengetahui perubahan variabel dependen jika variabel independen mengalami perubahan. Adapun hasil pengujiannya sebagai berikut:

Tabel 2. Hasil Pengujian Regresi Linier Sederhana Coefficients $^{\text {a }}$

Unstandardized

Coefficients

\begin{tabular}{|c|c|c|c|c|c|c|}
\hline \multicolumn{2}{|c|}{ Model } & B & Std. Error & Beta & $\mathrm{t}$ & Sig. \\
\hline \multirow[t]{2}{*}{1} & (Constant) & 11.598 & 2.668 & & 4.346 & .000 \\
\hline & Lingkungan kerja (X) & .781 & .078 & .746 & 10.022 & .000 \\
\hline
\end{tabular}

a. Dependent Variable: Kinerja Karyawan (Y)

Berdasarkan hasil pengujian pada tabel di atas, diperoleh persamaan regresi $\mathrm{Y}=11,598+0,781 \mathrm{X}$. Dari persamaan tersebut dijelaskan sebagai berikut:

1) Konstanta sebesar 11,598 diartikan jika lingkungan kerja tidak ada, maka telah terdapat nilai kinerja karyawan sebesar 11,598 point.

2) Koefisien regresi lingkungan kerja sebesar 0,781 , angka ini positif artinya setiap ada peningkatan lingkungan kerja sebesar 0,781 point maka kinerja karyawan juga akan mengalami peningkatan sebesar 0,781 point.

\section{b. Analisis Koefisien Korelasi}

Analisis koefisien korelasi dimaksudkan untuk mengetahui tingkat kekuatan hubungan dari variabel independen terhadap variabel dependen. Adapun hasil pengujian sebagai berikut:

Tabel 3. Hasil Pengujian Koefisien Korelasi Lingkungan kerja Terhadap Kinerja

\section{Karyawan.}

Correlations $^{\mathbf{b}}$

Lingkungan kerja $\quad$ Kinerja Karyawan

\begin{tabular}{llr|r} 
& & $\begin{array}{c}\text { Lingkungan kerja } \\
(\mathrm{X})\end{array}$ & $\begin{array}{r}\text { Kinerja Karyawan } \\
(\mathrm{Y})\end{array}$ \\
\hline Lingkungan kerja $(\mathrm{X})$ & Pearson Correlation & 1 & $.746^{* *}$ \\
\cline { 2 - 4 } & Sig. (2-tailed) & & .000 \\
\hline Kinerja Karyawan $(\mathrm{Y})$ & Pearson Correlation & $.746^{* *}$ & 1 \\
\cline { 2 - 4 } & Sig. (2-tailed) & .000 & \\
\hline
\end{tabular}

**. Correlation is significant at the 0.01 level (2-tailed).

b. Listwise $\mathrm{N}=82$ 
Berdasarkan hasil pengujian diperoleh nilai korelasi sebesar 0,746 artinya lingkungan kerja memiliki hubungan yang kuat terhadap kinerja karyawan.

\section{c. Analisis Koefisien Determinasi}

Analisis koefisien determinasi dimaksudkan untuk mengetahui besarnya persentase pengaruh dari variabel independen terhadap variabel dependen. Adapun hasil pengujian sebagai berikut:

Tabel 4. Hasil Pengujian Koefisien Determinasi Lingkungan kerja Terhadap Kinerja Karyawan.

\begin{tabular}{|c|c|c|c|c|}
\hline \multirow[b]{2}{*}{ Model } & \multicolumn{3}{|c|}{ Model Summary } & \multirow[b]{2}{*}{$\begin{array}{l}\text { Std. Error of } \\
\text { the Estimate }\end{array}$} \\
\hline & $\mathrm{R}$ & R Square & Adjusted R Square & \\
\hline 1 & $.746^{\mathrm{a}}$ & .557 & .551 & 2.806 \\
\hline
\end{tabular}

a. Predictors: (Constant), Lingkungan kerja (X)

Berdasarkan hasil pengujian diperoleh nilai determinasi sebesar 0,557 artinya lingkungan kerja memiliki kontribusi pengaruh sebesar 55,7\% terhadap kinerja karyawan, sedangkan sisanya sebesar $44,3 \%$ dipengaruhi oleh faktor lain yang tidak dilakukan penelitian.

\section{d. Uji Hipotesis}

Pengujian hipotesis dengan uji t digunakan untuk mengetahui hipotesis mana yang diterima. Rumusan hipotesis: Terdapat pengaruh yang signifikan lingkungan kerja terhadap kinerja karyawan.

Tabel 5. Hasil Uji Hipotesis Lingkungan kerja Terhadap Kinerja Karyawan. Coefficients $^{\mathrm{a}}$

\begin{tabular}{|c|c|c|c|c|c|}
\hline \multirow[b]{2}{*}{ Model } & \multicolumn{2}{|c|}{$\begin{array}{l}\text { Unstandardized } \\
\text { Coefficients }\end{array}$} & \multirow{2}{*}{$\begin{array}{c}\text { Standardized } \\
\text { Coefficients } \\
\text { Beta } \\
\end{array}$} & \multirow[b]{2}{*}{$\mathrm{t}$} & \multirow[b]{2}{*}{ Sig. } \\
\hline & $\mathrm{B}$ & Std. Error & & & \\
\hline $1 \quad$ (Constant) & 11.598 & 2.668 & & 4.346 & .000 \\
\hline Lingkungan kerja $(\mathrm{X})$ & .781 & .078 & .746 & 10.022 & .000 \\
\hline
\end{tabular}

a. Dependent Variable: Kinerja Karyawan (Y)

Berdasarkan hasil pengujian pada tabel di atas, diperoleh nilai t hitung $>\mathrm{t}$ tabel atau $(10,022>1,990)$, dengan demikian hipotesis yang diajukan bahwa terdapat pengaruh yang signifikan atara lingkungan kerja terhadap kinerja karyawan diterima.

\section{Pembahasan Hasil Penelitian}

\section{Kondisi Jawaban Responden Variabel Lingkungan kerja}

Berdasarkan jawaban responden, variabel lingkungan kerja diperoleh ratting score sebesar 3,401 berada di rentang skala 3,40 - 4,19 dengan kriteria baik atau setuju.

\section{Kondisi Jawaban Responden Variabel Kinerja Karyawan}

Berdasarkan jawaban responden, variabel kinerja karyawan diperoleh ratting score sebesar 3,816 berada di rentang skala 3,40 - 4,19 dengan kriteria baik atau setuju.

\section{Pengaruh Lingkungan kerja Terhadap Kinerja Karyawan}

Lingkungan kerja berpengaruh signifikan terhadap kinerja karyawan dengan persamaan regresi $\mathrm{Y}=11,598+0,781 \mathrm{X}$, nilai korelasi sebesar 0,746 atau memiliki 
hubungan yang kuat dengan kontribusi pengaruh sebesar 55,7\%. Pengujian hipotesis diperoleh nilai t hitung $>\mathrm{t}$ tabel atau $(10,022>1,990)$. Dengan demikian hipotesis yang diajukan bahwa terdapat berpengaruh signifikan antara lingkungan kerja terhadap kinerja karyawan diterima.

\section{KESIMPULAN DAN SARAN}

\section{Kesimpulan}

a. Variabel lingkungan kerja diperoleh ratting score sebesar 3,401 berada di rentang skala 3,40-4,19 dengan kriteria baik atau setuju.

b. Variabel kinerja karyawan diperoleh ratting score sebesar 3,816 berada di rentang skala 3,40 - 4,19 dengan kriteria baik atau setuju.

c. Lingkungan kerja berpengaruh signifikan terhadap kinerja karyawan dengan persamaan regresi $\mathrm{Y}=11,598+0,781 \mathrm{X}$, nilai korelasi sebesar 0,746 atau kuat dan kontribusi pengaruh sebesar 55,7\% sedangkan sisanya sebesar $44,3 \%$ dipengaruhi faktor lain. Uji hipotesis diperoleh nilai thitung > t tabel atau $(10,022>1,990)$.

\section{Saran}

a. Perusahaan sebaiknya memperhatikan setiap pelaksanaan lingkungan kerja khususnya pada bagian pelayanan karyawan kerja bagi karyawan dengan memperhatikan pelayanan karyawan yang kurang dan memperbaiki pelayanan karyawan yang sudah tidak layak untuk digunakan sehingga karyawan memiliki perasaan nyaman baik di lokasi kerja maupun di luar lokasi kerja. Perusahaan juga seharusnya memperhatikan kebutuhan setiap karyawan baik materil maupun non materil.

b. Sebagai bagian terpenting dari perusahaan, karyawan hendaknya lebih meningkatkan kinerja kerja melalui keseriusan mengikuti program- program yang mendukung kinerja. Setiap karyawan seharusnya bisa lebih meningkatkan kemampuan hasil yang dicapai di lapangan untuk mendukung peningkatan produksi perusahaan tersebut.

c. Peneliti selanjutnya seharusnya lebih menambah indikator untuk mengukur variabel lingkungan kerja dan kinerja kerja karyawan agar benar- benar bisa terukur dengan tepat.

\section{DAFTAR PUSTAKA}

Abdullah. M (2014). Manajemen dan Evaluasi Kinerja Karyawan. Yogyakarta: Penerbit Aswaja Pressindo.

Algifari. (2015). Analisis Regresi untuk Bisnis dan Ekonomi. Yogyakarta: BPFE.

Arikunto, Suharsimi (2014). Prosedur Penelitian Suatu Pendekatan Praktek. Jakarta: Rineka Cipta.

Bangun, Wilson. (2012). Manajemen Sumber Daya Manusia. Jakarta: Erlangga

Bejo Siswanto (2013) Manajemen Tenaga Kerja Rancangan dalam Pendayagunaan dan Pengembangan Unsur Tenaga Kerja. Bandung: Sinar Baru.

Dessler, G. (2006.). Manajemen Sumber Daya Manusia. Jilid II. Jakarta: Indeks.

Edi Sutrisno (2016). Manajemen Sumber Daya Manusia. Jakarta: Prenadamedia Group.

George Terry R \& Rue, Leslie W. Rue (2016). Dasar-Dasar Manajemen. Jakarta Bumi Aksara.

Gerry Dessler (2016). Human Resources Management. Prenticehall. London: International Inc.

Handoko (2016). Manajemen Personalia dan Sumberdaya Manusia. Yogyakarta: BPFE. 
Hasibuan, Malayu S.P. (2016). Manajemen Sumber Daya Manusia. Edisi Revisi. Jakarta: PT Bumi Aksara.

Imam Ghozali (2017). “Aplikasi Analisis Multivariate Dengan Program SPSS”. Edisi Kelima. Semarang: Badan Penerbit Undip.

Istijanto (2014) “Riset Sumber Daya Manusia”. Jakarta: PT. Gramedia Pustaka

Kharis, Ismu Fadli (2011). Studi Mengenai Impulse Buying dalam Penjualan Online. Semarang : Skripsi Universitas Diponegoro

Luthans Fred (2014). Organizational Behavior. Ney York: McGraw-Hill. New York.

Mangkunegara, Prabu Anwar. (2016). Evaluasi Kinerja SDM. Cetakan ke tujuh, PT Refika Aditama: Bandung.

Rao, Purba, (2012). Measuring Consumer Perceptions Through Factor Analysis. The Asian.

Robbins, P.S, \& Judge, A.T. (2003). Organizational Behavior. Jakarta: Salemba Empat.

Santoso, Singgih (2015). Menguasai Statistik Multivariat. Jakarta: PT Elex Media Komputindo.

Sedarmayanti (2016) Manajemen Sumber Daya Manusia, Reformasi Birokrasi dan Manajemen Karyawan Negeri Sipil, Cetakan Kelima, Bandung: PT Refika Aditama. Sudjana (2014). Metode Statistika. Bandung: Tarsido.

Sugiyono (2017). Metode Penelitian Administrasi dilengkapi dengan Metode R \& D. Bandung: Alfabeta.

Veithzal Rivai (2015) Manajemen Sumber Daya Manusia Untuk Perusahaan. Jakarta: Raja Grafindo Persada.

Wibowo (2015). Manajemen Kinerja. Jakarta: PT. Raja Grafindo Persada. 